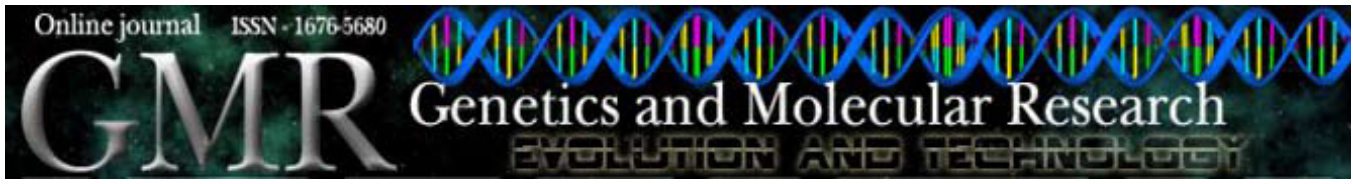

\title{
Association of lipase lipoprotein polymorphisms with high-density lipoprotein and triglycerides in elderly men
}

\author{
L.M.Q. Araújo ${ }^{1}$, M.S. Cendoroglo ${ }^{1}$, C.O. Gigek ${ }^{2}$, E.S. Chen ${ }^{2}$ and \\ M. de A.C. Smith ${ }^{2}$ \\ ${ }^{1}$ Disciplina de Geriatria e Gerontologia, \\ Universidade Federal de São Paulo, São Paulo, SP, Brasil \\ ${ }^{2}$ Disciplina de Genética, Universidade Federal de São Paulo, São Paulo, SP, Brasil \\ Corresponding author: L.M.Q. Araújo \\ E-mail: lara.mqaraujo@gmail.com
}

Genet. Mol. Res. 9 (1): 89-96 (2010)

Received September 14, 2009

Accepted October 8, 2009

Published January 19, 2010

\begin{abstract}
Lipoprotein lipase is essential for triglyceride hydrolysis. The polymorphisms S447X in exon 9 and HindIII in intron 8 have been associated with lower triglyceride levels and lower cardiovascular risk in adult men. We examined the association of these lipoprotein lipase polymorphisms with high-density lipoprotein (HDL) and triglyceride levels in elderly men. Blood samples were obtained from 87 elderly men, 48 of whom had cardiovascular disease and 39 (controls) had no history of cardiovascular events. The lipoprotein lipase polymorphisms were analyzed by PCR-RFLP. Allele frequencies were $\mathrm{H}-=27.9 \%$ and $\mathrm{X}=21.5 \%$. There were no significant differences in allele frequencies or blood lipid levels between cardiovascular disease and control groups. However, the $\mathrm{X}$ allele was associated with a lower triglyceride/HDL ratio, 2.30 vs 3.02 for $\mathrm{X}$ allele absent $(\mathrm{P}=0.03)$; the $\mathrm{H}-\mathrm{X}$ haplotype was associated with lower triglyceride levels compared to the $\mathrm{H}+\mathrm{S}$ haplotype (1.22 vs $1.58 \mathrm{mM}$, respectively) and a lower triglyceride/HDL ratio (2.29 vs 3.26, respectively). The $\mathrm{X}$ allele and $\mathrm{H}-\mathrm{X}$ haplotype were associated with lower triglyceride/HDL ratios in these elderly men, independent of the history of cardiovascular events.
\end{abstract}

Key words: Lipoprotein lipase; Polymorphism; Triglycerides; HDL cholesterol; Elderly 


\section{INTRODUCTION}

Stroke risk doubles each decade after 55 years of age (Wolf et al., 1992), and the probability of coronary artery disease (CAD) in men is also higher with aging (Barreto et al., 2003). There is an incidence peak of events in elderly people. Part of these events is explained by lipoprotein metabolism and the relationship between HDL cholesterol and triglyceride-rich lipoproteins (Assmann, 2004; Windler et al., 2007). Among older patients with myocardial infarction, HDL cholesterol level is on average $15 \mathrm{mg} / \mathrm{dL}$ lower than in controls (Assmann and Gotto Jr., 2004), and the higher ratio of triglycerides to HDL is a strong risk predictor (Lindenstrom et al., 1994; Gaziano et al., 1997).

Lipoprotein lipase is a key enzyme in triglyceride hydrolysis, and its gene is located on chromosome 8p22, with 9 exons and $29.6 \mathrm{~kb}$. Genetic variants can lead to lipid disorders and increase atherosclerosis risk. The HindIII polymorphism is a base transition of thymine (T) to guanine $(\mathrm{G})$ at position +495 in intron 8 , which abolishes the restriction site for the enzyme HindIII and the $\mathrm{H}$ - allele has less affinity for a transcription regulator factor of the LPL gene. The S447X polymorphism is characterized by the substitution of cytosine (C) by guanine $(\mathrm{G})$ at position 1595 in exon 9, resulting in a premature stop codon, which removes the last two amino acids of the protein. The $\mathrm{X}$ allele is associated with higher LPL activity (Hata et al., 1990; Kobayashi et al., 1992; Chen et al., 2008).

In the literature, $\mathrm{X}$ allele frequency ranges from 10 to $20 \%$, while the frequency of genotype XX is $1 \%$. H- allele frequency ranges from 21 to $30 \%$, while the frequency of genotype $\mathrm{HH}$ is 7 to $10 \%$. Previous studies in Brazilians showed the $\mathrm{X}$ allele in 12 to $17.8 \%$ and H- allele in 28.4 to 34.8\% (Almeida et al., 2007; Gigek et al., 2007; Sepetiba et al., 2007).

The exact mechanism of action of these polymorphisms is however controversial, but the $\mathrm{X}$ allele and $\mathrm{H}$ - allele are associated with protection against myocardial infarction and ischemic stroke. It is probable that benefits are through lipid metabolism, although some research shows an effect independent of blood lipid levels (Morrison et al., 2002).

We studied elderly men to determine if these polymorphisms are associated with HDL and triglyceride levels in this group.

\section{MATERIAL AND METHODS}

\section{Population}

We included a total of 87 men of 65 years of age or more from the Division of Geriatrics and Gerontology of UNIFESP (Federal University of São Paulo); 48 had had acute coronary syndrome or ischemic stroke [cardiovascular (CV) group], and 39 had had no previous cardiovascular event, its equivalents or diabetes (control group) (Sposito et al., 2007). All patients with acute disease, uncontrolled diabetes or systemic disease were excluded. Subjects were considered to be positive for cardiovascular disease when they self-reported previous myocardial infarction or angina pectoris with Intensive Care Unit admission or ischemic stroke and taking specific medication prescribed by physicians. The clinical information obtained pertained to personal and family medical history and lifestyle. Physicians performed a physical examination with weight, height and blood pressure measurements. Blood samples were collected after $12 \mathrm{~h}$ fasting for laboratory procedures. The Research Ethics Committee approved this study, and all participants signed informed consent form, according to the Helsinki Declaration. 


\section{Laboratory exams and DNA extraction}

Lipid and lipid fraction measurements were performed using routine enzymatic tests. We calculated risk ratio $\mathrm{I}=$ total cholesterol to HDL, desirable, equal to or less than 4.9; risk ratio II $=\mathrm{LDL}$ to $\mathrm{HDL}$, desirable, equal to or less than 2.4 , and risk ratio III $=$ triglyceride to HDL, desirable, equal to or less than 3.8 (Anonymous, 2001). Blood was collected in tubes containing $0.1 \%$ EDTA, and genomic DNA was isolated using a modification of the procedure reported by Lahiri and Nurnberger Jr. (1991).

\section{Polymorphism detection}

Primer sequences, polymerase chain reaction (PCR) conditions and restriction enzyme digestions were as follows (oligonucleotides were synthesized by Promicro, São Paulo, Brazil). For the HindIII polymorphism, the forward primer was 5'-GATGTCTACCTGGATAAT CAAAG-3, and the reverse primer was 5'-CTTCAGCTAGACATTGCTAGTGT'-3. PCR was carried out in a $50-\mathrm{mL}$ reaction volume containing $100 \mathrm{ng}$ genomic DNA, $0.4 \mathrm{mM}$ of each primer, $0.2 \mathrm{mM}$ dNTPs (Invitrogen, Carlsbad, CA, USA), $2 \mathrm{mM} \mathrm{MgCl}_{2}$ in $10 \%$ PCR buffer and 1 U DNA polymerase (DNA directed; Invitrogen, São Paulo, Brazil). PCR involved an initial 5 -min denaturation at $96^{\circ} \mathrm{C}, 40$ cycles of denaturation at $94^{\circ} \mathrm{C}$ for $1 \mathrm{~min}$, annealing at $57^{\circ} \mathrm{C}$ for $1 \mathrm{~min}$ and extension at $72^{\circ} \mathrm{C}$ for $1 \mathrm{~min}$, with a final extension at $72^{\circ} \mathrm{C}$ for $7 \mathrm{~min}$. Aliquots of 8 $\mathrm{mL}$ of the PCR products were digested with 2.5 U HindIII (MBI Fermentas, Vilnius, Lithuania) at $37^{\circ} \mathrm{C}$ for $4 \mathrm{~h}$. The common $\mathrm{H}+$ allele has one restriction site and produces two fragments of 210 and $140 \mathrm{bp}$. For the S447X polymorphism, the forward primer was 5'-TACACTAGCAAT GTCTAGGTGA-3', and the reverse primer was 5'-TCAGCTTTAGCCCAGAATGC-3'. The PCR volume was as described for HindIII, with initial denaturation for 5 min at $94^{\circ} \mathrm{C}, 40$ cycles of denaturation for $1 \mathrm{~min}$ at $94^{\circ} \mathrm{C}$, annealing for $1 \mathrm{~min}$ at $60^{\circ} \mathrm{C}$ and extension for $30 \mathrm{~s}$ at $72^{\circ} \mathrm{C}$, and a final extension for $7 \mathrm{~min}$ at $72^{\circ} \mathrm{C}$. Samples were digested with $2.5 \mathrm{U}$ MnlI (MBI Fermentas) for $4 \mathrm{~h}$ at $37^{\circ} \mathrm{C}$. The polymorphic $\mathrm{X}$ allele has two restriction sites and produces three fragments of 285, 250 and $203 \mathrm{bp}$. Restriction fragment length polymorphism (RFLP) products were analyzed on $3 \%$ agarose gel and stained with ethidium bromide.

\section{Statistical analysis}

SAS 9.1 (Statistical Analysis System, Cary, NC, USA) was used to perform the chisquare test, analysis of variance, logistic regression analysis, and the Student $t$-test. Genotype and allele frequencies were calculated by allele counting (Emery, 1986). Genotype distribution was investigated in relation to Hardy-Weinberg equilibrium using the "Genepop on the web" website (Garnier-Gere and Dillmann, 1992).

\section{RESULTS}

The mean age was 76 years (range: $65-90$ years) and $77 \%$ were Caucasian. In cardiovascular cases, $52 \%$ (25/48) had suffered ischemic stroke, $42 \%(20 / 48)$ acute coronary syndrome and 6\% (3/48) both. The prevalence of hypertension, low HDL levels and cardiovascular family cases was higher in the CV group when compared to control subjects (Table 1). 


\begin{tabular}{|c|c|c|c|}
\hline Characteristics & Controls $(\mathrm{N}=39)$ & $\mathrm{CV}$ cases $(\mathrm{N}=48)$ & $P$ \\
\hline Age (years) & $75.84 \pm 5.83$ & $77.33 \pm 6.77$ & 0.2819 \\
\hline Hypertension & $18(46.15 \%)$ & $34(70.83 \%)$ & $0.0342^{*}$ \\
\hline SBP (mmHg) & $136.22 \pm 16.64$ & $144.48 \pm 24.07$ & 0.0626 \\
\hline $\mathrm{DBP}(\mathrm{mmHg})$ & $78.97 \pm 9.97$ & $84.41 \pm 9.74$ & $0.0121^{*}$ \\
\hline BMI $\left(\mathrm{kg} / \mathrm{m}^{2}\right)$ & $26.78 \pm 3.84$ & $26.12 \pm 3.88$ & 0.4387 \\
\hline Cholesterol (mM) & $4.70 \pm 0.93$ & $4.69 \pm 0.98$ & 0.9361 \\
\hline LDL-C $(\mathrm{mM})$ & $2.72 \pm 0.86$ & $2.88 \pm 0.92$ & 0.4116 \\
\hline HDL- C (mM) & $1.29 \pm 0.29$ & $1.16 \pm 0.23$ & $0.0196^{*}$ \\
\hline Triglycerides (mM) & $1.64 \pm 0.98$ & $1.47 \pm 0.82$ & 0.4068 \\
\hline Risk ratio I & $3.84 \pm 1.22$ & $4.18 \pm 1.17$ & 0.1864 \\
\hline Risk ratio II & $2.20 \pm 0.93$ & $2.58 \pm 0.99$ & 0.0759 \\
\hline Risk ratio III & $2.62(2.12$ to 3.26$)$ & $2.69(2.31$ to 3.14$)$ & 0.8480 \\
\hline Family CHD & $5(12.82 \%)$ & $17(35.42 \%)$ & $0.0278^{*}$ \\
\hline Current smoker & $5(12.82 \%)$ & $6(12.50 \%)$ & 1.00 \\
\hline Previous smoker & $18(46.15 \%)$ & $27(56.25 \%)$ & 0.47 \\
\hline Regular exercise & $22(56.41 \%)$ & $26(54.17 \%)$ & 1.00 \\
\hline
\end{tabular}

Data are reported as means $\pm \mathrm{SD}$ and number with percent in parentheses, except for Risk ratio III. $* \mathrm{P}<0.05 . \mathrm{SBP}$ = systolic blood pressure; DBP = diastolic blood pressure; $\mathrm{BMI}=$ body mass index; Risk ratio $\mathrm{I}=$ total cholesterol $/$ HDL-C; Risk ratio II = LDL-C/HDL-C; Risk ratio III = triglyceride/HDL-C (geometric mean 95\%CI); family CHD $=$ family history of premature cardiovascular disease.

In Table 2, we present the genotype frequency in control and CV groups, and there were no differences between them. The S447X and the HindIII polymorphisms were in linkage disequilibrium. The $\mathrm{H}-$ allele and $\mathrm{X}$ allele frequencies in the $\mathrm{CV}$ group were 25.53 and $22.34 \%$ and 30.77 and $20.51 \%$ in the control group, respectively. There were no differences in allele frequencies between the groups.

Table 2. Comparison of the genotype frequencies of S447X and HindIII polymorphisms of the LPL gene in
controls and cardiovascular (CV) cases.
\begin{tabular}{lcccc}
\hline Genotype & Controls & CV cases & Total & P \\
\hline $\mathrm{H}+\mathrm{H}^{+}$ & $19(48.72 \%)$ & $26(55.32 \%)$ & $45(52.33 \%)$ & $0.762^{1}$ \\
$\mathrm{H}+\mathrm{H}-$ & $16(41.03 \%)$ & $18(38.30 \%)$ & $34(39.53 \%)$ & \\
$\mathrm{H}-\mathrm{H}-$ & $4(10.26 \%)$ & $3(6.38 \%)$ & $7(8.14 \%)$ & $0.828^{2}$ \\
$\mathrm{SS}$ & $23(58.97 \%)$ & $26(55.32 \%)$ & $49(56.98 \%)$ & \\
$\mathrm{SX}$ & $16(41.03 \%)$ & $21(44.68 \%)$ & $37(43.02 \%)$ & 0 \\
$\mathrm{XX}$ & 0 & 0 & & 0 \\
\hline
\end{tabular}

Data are reported as number with percent in parentheses. ${ }^{1}$ Fisher exact test; ${ }^{2}$ Pearson chi-square test.

The influence of these polymorphisms on lipid blood levels was determined by comparing the presence and absence of $\mathrm{H}$ - and $\mathrm{X}$ alleles in all subjects. The presence of $\mathrm{X}$ allele was associated with lower triglyceride/HDL ratio (risk ratio $\mathrm{III}=2.30,95 \% \mathrm{CI}=1.92$ to 2.76 vs $3.02,95 \% \mathrm{CI}=2.53$ to 3.57 - for $\mathrm{X}$ allele absent, $\mathrm{P}=0.03$ ), as shown in Table 3 . The HindIII alleles were not associated with risk ratio and lipid levels. Medications to treat lipid disorders were distributed equally between $\mathrm{X}$ and $\mathrm{H}$ - allele carriers and non-carriers (data not shown; $\mathrm{P}$ $=0.78$ and $\mathrm{P}=0.53$, respectively). In Table 4 , the $\mathrm{H}-\mathrm{X}$ haplotype was associated with lower triglyceride levels compared to the $\mathrm{H}+\mathrm{S}$ haplotype $(1.22$ vs $1.58 \mathrm{mM}$, geometric mean $95 \% \mathrm{CI}$, respectively) and lower triglyceride/HDL ratio (risk ratio $\mathrm{III}=2.29,95 \% \mathrm{CI}=1.82$ to $2.86 \mathrm{vs}$ $3.26,95 \% \mathrm{CI}=2.58$ to 4.11 ). There were no differences in the medications used to treat lipid disorders between any polymorphism haplotype carriers (data not shown; $\mathrm{P}=0.81$ ). 
Table 3. Blood lipid levels according to the HindIII and the S447X polymorphisms of the LPL gene in all the sample.

\begin{tabular}{|c|c|c|c|c|c|c|}
\hline \multirow[t]{2}{*}{ Lipid profile } & \multicolumn{3}{|c|}{$\operatorname{HindIII}(\mathrm{N}=86)$} & \multicolumn{3}{|c|}{ S447X $(\mathrm{N}=86)$} \\
\hline & $\begin{array}{l}\text { H- allele absent } \\
\quad(\mathrm{N}=45)\end{array}$ & $\begin{array}{l}\text { H- allele present } \\
\qquad(\mathrm{N}=41)\end{array}$ & $\mathrm{P}$ & $\begin{array}{c}\mathrm{X} \text { allele present } \\
(\mathrm{N}=37)\end{array}$ & $\begin{array}{c}\mathrm{X} \text { allele absent } \\
(\mathrm{N}=49)\end{array}$ & $\mathrm{P}$ \\
\hline Cholesterol (mM) & $4.62 \pm 0.94$ & $4.76 \pm 0.99$ & 0.49 & $4.76 \pm 0.90$ & $4.65 \pm 1.01$ & 0.61 \\
\hline LDL-C (mM) & $2.72 \pm 0.81$ & $2.89 \pm 0.98$ & 0.38 & $2.88 \pm 0.88$ & $2.76 \pm 0.89$ & 0.55 \\
\hline HDL-C (mM) & $1.19 \pm 0.29$ & $1.24 \pm 0.24$ & 0.49 & $1.27 \pm 0.27$ & $1.17 \pm 0.26$ & 0.09 \\
\hline Triglycerides (mM) & $1.69 \pm 1.12$ & $1.39 \pm 0.54$ & 0.12 & $1.35 \pm 0.56$ & $1.71 \pm 1.07$ & 0.06 \\
\hline Risk ratio I & $4.08 \pm 1.29$ & $3.98 \pm 1.12$ & 0.69 & $3.92 \pm 1.19$ & $4.13 \pm 1.21$ & 0.43 \\
\hline Risk ratio II & $2.39 \pm 0.99$ & $2.43 \pm 0.98$ & 0.85 & $2.39 \pm 1.01$ & $2.43 \pm 0.96$ & 0.84 \\
\hline Risk ratio III & 2.90 (2.37 to 3.52$)$ & $2.42(2.05$ to 2.83$)$ & 0.15 & $2.30(1.92$ to 2.76$)$ & $3.02(2.53$ to 3.57$)$ & $0.03 *$ \\
\hline Non-HDL-C (mM) & $3.43 \pm 0.95$ & $3.52 \pm 1.00$ & 0.85 & $3.49 \pm 0.95$ & $3.48 \pm 1.00$ & 0.95 \\
\hline
\end{tabular}

Data are reported as means $\pm \mathrm{SD}$, except for Risk ratio III. $* \mathrm{P}<0.05$. Risk ratio $\mathrm{I}=$ total cholesterol/HDL-C; Risk ratio II $=$ LDL-C/HDL-C; Risk ratio III = triglyceride/HDL-C (geometric mean 95\% CI); non-HDL-C $=$ total cholesterol-HDL-C.

\begin{tabular}{|c|c|c|c|}
\hline Lipid profile & $\begin{array}{c}\mathrm{H}+\mathrm{S}(\mathrm{CV} \text { risk }) \\
\quad(\mathrm{N}=32)\end{array}$ & $\begin{array}{c}\mathrm{H}-\mathrm{X}(\mathrm{CV} \text { protection }) \\
(\mathrm{N}=24)\end{array}$ & $P$ \\
\hline Cholesterol (mM) & $4.65 \pm 1.06$ & $4.84 \pm 1.04$ & 0.5092 \\
\hline LDL-C** $(\mathrm{mM})$ & $2.82 \pm 2.34$ to 3.41 & $2.85 \pm 2.47$ to 3.28 & 0.9429 \\
\hline HDL-C (mM) & $1.14 \pm 0.25$ & $1.24 \pm 0.23$ & 0.1299 \\
\hline Triglycerides** (mM) & $1.58 \pm 1.32$ to 1.90 & $1.22 \pm 1.03$ to 1.45 & $0.0449 *$ \\
\hline Risk ratio I & $4.27 \pm 1.31$ & $4.04 \pm 1.22$ & 0.5354 \\
\hline Risk ratio II & $2.52 \pm 12.46$ & $2.52 \pm 1.08$ & 0.9512 \\
\hline Risk ratio III & $3.26 \pm 2.58$ to 4.11 & $2.29 \pm 1.82$ to 2.86 & $0.0353^{*}$ \\
\hline Non-HDL-C (mM) & $3.51 \pm 1.06$ & $3.60 \pm 1.08$ & 0.7609 \\
\hline
\end{tabular}

Data are repoted as means $\pm \mathrm{SD} . * \mathrm{P}<0.05 ; * *$ Geometric mean $95 \% \mathrm{CI}$. Risk ratio I $=$ total cholesterol/HDL-C; Risk ratio II $=$ LDL-C/HDL-C; Risk ratio III $=$ triglyceride/HDL-C; non-HDL-C $=$ total cholesterol-HDL-C. CV $=$ cardiovascular disease.

There were no differences between haplotype carriers in other lipids and their clinically recommended lipid levels (Table 5). Considering the clinical endpoint, there was a tendency $(\mathrm{P}=0.06)$ towards less family history of premature cardiovascular disease in $\mathrm{H}-\mathrm{X}$ haplotype carriers (Table 6).

Table 5. Proportion of $\mathrm{H}+\mathrm{S}$ and H-X haplotypes of the LPL gene carriers with clinically recommended blood lipid levels and risk ratios of cardiovascular (CV) disease in all the sample.

\begin{tabular}{|c|c|c|c|}
\hline Desirable lipid parameters & $\begin{array}{c}\mathrm{H}+\mathrm{S}(\mathrm{CV} \text { risk }) \\
(\mathrm{N}=32)\end{array}$ & $\begin{array}{c}\mathrm{H}-\mathrm{X}(\mathrm{CV} \text { protection }) \\
(\mathrm{N}=24)\end{array}$ & $\mathrm{P}$ \\
\hline LDL-C less than $2.56 \mathrm{mM}$ & $15(48.39 \%)$ & $10(41.67 \%)$ & 0.6196 \\
\hline HDL-C greater than or equal to $1.03 \mathrm{mM}$ & $21(61.63 \%)$ & $20(83.33 \%)$ & 0.1386 \\
\hline Triglycerides less than $1.69 \mathrm{mM}$ & $19(59.38 \%)$ & $17(70.83 \%)$ & 0.3758 \\
\hline Risk ratio I less than or equal to 4.9 & $24(75 \%)$ & $17(70.83 \%)$ & 0.7275 \\
\hline Risk ratio II less than or equal to 2.4 & $17(54.84 \%)$ & $14(58.33 \%)$ & 0.7950 \\
\hline Risk ratio III less than or equal to 3.8 & $10(31.25 \%)$ & $4(16.67 \%)$ & 0.2123 \\
\hline Non-HDL-C less than $3.33 \mathrm{mM}$ & $16(50 \%)$ & $11(45.83 \%)$ & 0.7575 \\
\hline
\end{tabular}

Data are reported as number with percent in parentheses. Risk ratio $\mathrm{I}=$ total cholesterol/HDL-C; Risk ratio II $=$ LDL-C/HDL-C; Risk ratio III = triglyceride/HDL-C; non-HDL-C $=$ total cholesterol-HDL-C. 


\begin{tabular}{lccc}
\multicolumn{4}{l}{ Table 6. History of cardiovascular $(\mathrm{CV})$ disease in $\mathrm{H}+\mathrm{S}$ and $\mathrm{H}-\mathrm{X}$ haplotypes of the LPL gene carriers in all the sample. } \\
\hline History of cardiovascular disease & $\mathrm{H}+\mathrm{S}(\mathrm{CV}$ risk $)$ & $\mathrm{H}-\mathrm{X}(\mathrm{CV}$ protection $)$ & $\mathrm{P}$ \\
& $(\mathrm{N}=32)$ & $(\mathrm{N}=24)$ & 0.8767 \\
\hline Personal (case group) & $18(56.25 \%)$ & $13(54.17 \%)$ & 0.0614 \\
\hline
\end{tabular}

Data are reported as number with percent in parentheses.

\section{DISCUSSION}

In the present study, the $\mathrm{X}$ allele was associated with a lower triglyceride/HDL-C ratio, which points to benefits in triglyceride metabolism. The H- allele was not associated with blood lipids. Nevertheless, H-X haplotypes were associated with lower triglyceride levels and lower triglyceride/HDL-C ratio when compared to the $\mathrm{H}+\mathrm{S}$ haplotype. The frequency of $\mathrm{H}$ - allele was $27.9 \%$ and of $\mathrm{X}$ allele $21.5 \%$, with no differences between CV and control groups.

Medications to treat lipid disorders could reduce triglyceride levels and elevate HDL levels and, as a consequence, could be a factor that reduced our findings of the association between these polymorphism and lipid profile in these subjects. However, we expect that these medications influenced all groups in the same proportion because they were equally distributed between all groups - common and uncommon allele carriers and CV and control groups.

In our sample, $77 \%$ were considered to be Caucasian because of parental geographic origin and skin color. In the methods, we decided to ask about parental origin plus personal skin color due to allele frequencies being lower in black people. It seems that there are no differences between Hispanics and white non-Hispanics (Razzaghi et al., 2000). Hence, we understand that this sample is comparable to Caucasians in other studies.

Considering that lipoproteins may be influenced by way of life and genetic polymorphism, the influence of these polymorphisms on lipoprotein levels could be minimized by these elderly men's lifestyle. Current smoking prevalence was $12 \%$ and we observed a $70 \%$ reduction compared to previous smoking. More than half of the subjects were practicing physical exercise.

There is little information about impact of age on expression of these polymorphisms, and it is possible that there is a difference between elderly and younger adults. The frequency of LPL HindIII polymorphism was $50 \%$ in Russians older than 90 years of age. In elderly Brazilians with age range from 66 to 97 years (mean of 79 years), the $\mathrm{H}$ - allele was found in $34.8 \%$ and the $\mathrm{X}$ allele in $17.6 \%$. Allele $\mathrm{H}+$ was associated with coronary disease in both studies (Malygina et al., 2001; Gigek et al., 2007). In our study, allele H- frequency was slightly lower (27.9\%), possibly due to the lower mean age (76 years) or the sample size. It is known that HDL level shows an age-X polymorphism interaction, with association of $\mathrm{X}$ allele after 10 years of age and a reduction of effect after 30 years (Chen et al., 2001; Hallman et al., 2001; Thu et al., 2006). Thus, interaction between age, polymorphisms and lipoprotein requires further research. Some studies have also shown that the impact of these polymorphisms on females is not significant (Ahn et al., 1993; Mattu et al., 1994; Humphries et al., 1998; Nicklas et al., 2000; McGladdery et al., 2001; Van Bockxmeer et al., 2001).

Other studies have evaluated these polymorphisms in Brazilian subjects younger than the subjects in our study. A case-control study with 12 normolipidemic subjects with X allele 
(mean age: 36 years) and in 13 control subjects without this allele (mean age: 33 years) has shown no differences in chylomicron metabolism evaluated by doubly labeled chylomicronlike emulsion injected intravenously (Almeida et al., 2003). In another case-control study, X allele was associated with lower triglyceride levels and cardiovascular protection in CAD patients of less than 55 years and 150 controls (Almeida et al., 2007). The S447 and HindIII LPL polymorphisms were assessed in 309 non-diabetic patients with angiographic CAD (mean age: 59.1 years) and in 197 controls (mean age: 55.3 years) in a southern Brazilian population of European descent. H- allele was associated with lower triglycerides and higher HDL-C and the $\mathrm{X}$ allele was associated with lower triglyceride levels in males. Carriers of H-S and $\mathrm{H}-\mathrm{X}$ haplotypes showed lower triglycerides and increased HDL-C levels when compared to the $\mathrm{H}+\mathrm{S}$ haplotype, and the $\mathrm{H}-$ haplotype was associated with a significant protective effect against CAD in the male subjects (Almeida et al., 2003).

In conclusion, our results in elderly men show that carriers of $\mathrm{X}$ allele have a better triglyceride/HDL-C ratio and that $\mathrm{H}-\mathrm{X}$ haplotype carriers have lower triglyceride levels and a better triglyceride/HDL-C ratio. H- allele was not associated with blood lipids or cardiovascular events. Knowledge of polymorphism in this population is a path to a better understanding of genetic influence in triglyceride metabolism and cardiovascular risk in the elderly.

\section{ACKNOWLEDGMENTS}

Research supported by the Fundação de Amparo à Pesquisa do Estado de São Paulo (FAPESP) and the Conselho Nacional de Pesquisa (CNPq), Brazil. There are no conflicts of interest in this study. We thank Frederico Moreira (Statconsultoria) who performed the statistical analysis. We appreciate the dedicated work of the survey teams.

\section{REFERENCES}

Ahn YI, Kamboh MI, Hamman RF, Cole SA, et al. (1993). Two DNA polymorphisms in the lipoprotein lipase gene and their associations with factors related to cardiovascular disease. J. Lipid Res. 34: 421-428.

Almeida KA, Schreiber R, Amancio RF, Bydlowski SP, et al. (2003). Metabolism of chylomicron-like emulsions in carriers of the S447X lipoprotein lipase polymorphism. Clin. Chim. Acta 335: 157-163.

Almeida KA, Strunz CM, Maranhao RC and Mansur AP (2007). The S447X polymorphism of lipoprotein lipase: effect on the incidence of premature coronary disease and on plasma lipids. Arq. Bras. Cardiol. 88: 297-303.

Anonymous (2001). Executive Summary of the Third Report of the National Cholesterol Education Program (NCEP) Expert Panel on Detection, Evaluation, and Treatment of High Blood Cholesterol in Adults (Adult Treatment Panel III). JAMA 285: 2486-2497.

Assmann G (2004). Symposium introduction: Improved cardiovascular risk reduction: the evidence for raising HDL cholesterol. Br. J. Cardiol. 11: S1-S2.

Assmann G and Gotto AM Jr (2004). HDL cholesterol and protective factors in atherosclerosis. Circulation 109: III-8-III-14.

Barreto SM, Passos VM, Cardoso AR and Lima-Costa MF (2003). Quantifying the risk of coronary artery disease in a community: the Bambui Project. Arq. Bras. Cardiol. 81: 549-561.

Chen Q, Razzaghi H, Demirci FY and Kamboh MI (2008). Functional significance of lipoprotein lipase HindIII polymorphism associated with the risk of coronary artery disease. Atherosclerosis 200: 102-108.

Chen W, Srinivasan SR, Elkasabany A, Ellsworth DL, et al. (2001). Influence of lipoprotein lipase serine 447 stop polymorphism on tracking of triglycerides and HDL cholesterol from childhood to adulthood and familial risk of coronary artery disease: the Bogalusa Heart Study. Atherosclerosis 159: 367-373.

Emery AE (1986). Methodology in Medical Genetics - An Introduction to Statistical Methods. Longman, Edinburgh.

Garnier-Gere P and Dillmann C (1992). A computer program for testing pairwise linkage disequilibria in subdivided populations. J. Hered. 83: 239. 
Gaziano JM, Hennekens CH, O’Donnell CJ, Breslow JL, et al. (1997). Fasting triglycerides, high-density lipoprotein, and risk of myocardial infarction. Circulation 96: 2520-2525.

Gigek CO, Chen ES, Cendoroglo MS, Ramos LR, et al. (2007). Association of lipase lipoprotein polymorphisms with myocardial infarction and lipid levels. Clin. Chem. Lab. Med. 45: 599-604.

Hallman DM, Srinivasan SR, Elkasabany A, Boerwinkle E, et al. (2001). The Ser(447)-Stop polymorphism of lipoprotein lipase is associated with variation in longitudinal serum high-density lipoprotein-cholesterol profiles: the Bogalusa Heart Study. Metabolism 50: 894-904.

Hata A, Robertson M, Emi M and Lalouel JM (1990). Direct detection and automated sequencing of individual alleles after electrophoretic strand separation: identification of a common nonsense mutation in exon 9 of the human lipoprotein lipase gene. Nucleic Acids Res. 18: 5407-5411.

Humphries SE, Nicaud V, Margalef J, Tiret L, et al. (1998). Lipoprotein lipase gene variation is associated with a paternal history of premature coronary artery disease and fasting and postprandial plasma triglycerides: the European Atherosclerosis Research Study (EARS). Arterioscler. Thromb. Vasc. Biol. 18: 526-534.

Kobayashi J, Nishida T, Ameis D, Stahnke G, et al. (1992). A heterozygous mutation (the codon for Ser447 - a stop codon) in lipoprotein lipase contributes to a defect in lipid interface recognition in a case with type I hyperlipidemia. Biochem. Biophys. Res. Commun. 182: 70-77.

Lahiri DK and Nurnberger JI Jr (1991). A rapid non-enzymatic method for the preparation of HMW DNA from blood for RFLP studies. Nucleic Acids Res. 19: 5444.

Lindenstrom E, Boysen G and Nyboe J (1994). Influence of total cholesterol, high density lipoprotein cholesterol, and triglycerides on risk of cerebrovascular disease: the Copenhagen City Heart Study. BMJ 309: 11-15.

Malygina NA, Melent'ev AS, Kostomarova IV, Melent'ev IA, et al. (2001). [Connection of HindIII-polymorphism in the lipoprotein lipase gene with myocardial infarct and life span in elderly ischemic heart disease patients]. Mol. Biol. 35: 787-791.

Mattu RK, Needham EW, Morgan R, Rees A, et al. (1994). DNA variants at the LPL gene locus associate with angiographically defined severity of atherosclerosis and serum lipoprotein levels in a Welsh population. Arterioscler. Thromb. 14: 1090-1097.

McGladdery SH, Pimstone SN, Clee SM, Bowden JF, et al. (2001). Common mutations in the lipoprotein lipase gene (LPL): effects on HDL-cholesterol levels in a Chinese Canadian population. Atherosclerosis 156: 401-407.

Morrison AC, Ballantyne CM, Bray M, Chambless LE, et al. (2002). LPL polymorphism predicts stroke risk in men. Genet. Epidemiol. 22: 233-242.

Nicklas BJ, Ferrell RE, Rogus EM, Berman DM, et al. (2000). Lipoprotein lipase gene variation is associated with adipose tissue lipoprotein lipase activity, and lipoprotein lipid and glucose concentrations in overweight postmenopausal women. Hum. Genet. 106: 420-424.

Razzaghi H, Aston CE, Hamman RF and Kamboh MI (2000). Genetic screening of the lipoprotein lipase gene for mutations associated with high triglyceride/low HDL-cholesterol levels. Hum. Genet. 107: 257-267.

Sepetiba RJ, Andrade J, Hirata RD, Hirata MH, et al. (2007). Lipoprotein lipase $P v u I I$ polymorphism is associated with variations in serum lipid levels in non-diabetic pregnant women. Braz. J. Med. Biol. Res. 40: 919-926.

Sposito AC, Caramelli B, Fonseca FA, Bertolami MC, et al. (2007). [IV Brazilian Guideline for Dyslipidemia and Atherosclerosis Prevention: Department of Atherosclerosis of Brazilian Society of Cardiology]. Arq. Bras. Cardiol. 88 (Suppl 1): 2-19.

Thu NN, Mai TT, Ohmori R, Kuroki M, et al. (2006). Plasma triglyceride and HDL-cholesterol concentrations in Vietnamese girls are affected by lipoprotein lipase, but not apolipoprotein CIII polymorphism. J. Nutr. 136: 1488-1492.

Van Bockxmeer FM, Liu Q, Mamotte C, Burke V, et al. (2001). Lipoprotein lipase D9N, N291S and S447X polymorphisms: their influence on premature coronary heart disease and plasma lipids. Atherosclerosis 157: 123-129.

Windler E, Schoffauer M and Zyriax BC (2007). The significance of low HDL-cholesterol levels in an ageing society at increased risk for cardiovascular disease. Diab. Vasc. Dis. Res. 4: 136-142.

Wolf PA, D’Agostino RB, O’Neal MA, Sytkowski P, et al. (1992). Secular trends in stroke incidence and mortality. The Framingham Study. Stroke 23: 1551-1555. 